\title{
Key Aspects of Shaping HR Strategy of MC Kolmar LLC at Various Stages of the Company's Life Cycle
}

\author{
Anna E. Tsivileva 1[ORCID 0000-0002-3205-2046], \\ Sergei S. Golubev 2*[ORCID 0000-0001-8745-6235]
}

\author{
${ }^{1}$ All-Russia Scientific and Research Institute “Center”, Moscow, Russia \\ ${ }^{2}$ Moscow Polytechnic University, Moscow, Russia \\ Sergei.golubev56@mail.ru
}

\begin{abstract}
The purpose of the conducted research is to highlight the main directions and tools planned for application in HR-strategy of coal mining company to improve the efficiency of work with personnel, increase the quality of human capital, as well as to increase the attractiveness of the company for employees at different stages of the life cycle of the organization. The article considers the main aspects of formation of HR-strategy of Kolmar Coal Mining Company, which the authors called "Transition Strategy". The article identifies the basic principles and tools for working with personnel at different stages: recruiting, hiring, training and working in the organization. The elements of corporate culture are also considered, the directions of its development in accordance with the stages of the life cycle of the organization are determined. The choice of the basic HR-strategy and its main components was made, and the potential and directions of strategic development of the company were determined. The main cohesive theoretical basis for the development of Transition Strategy principles and tools was the organization life cycle theory and the managerial style model by Ichak Kalderon Adizes. Using these theoretical foundations and elements of strategic analysis, the authors defined the stage of the company's life cycle at the moment, established the correspondence of the necessary management styles to this stage. Based on the theoretical tools, as well as applying other developments of leading experts in the theory of management, the authors have built a system of measures in the field of personnel management consistent with the current state of the Kolmar Coal Mining Company and outlined the main elements of functional strategies for work with personnel, relevant to the strategic directions of development of this area of the company activities. The research carried out in this paper will enable the systematic structuring of HR work in the company and build the basic principles of corporate culture in the perspective of the period 2022-2025, and effectively solve the problem of increasing the number of employees in accordance with the growth rate of the company.
\end{abstract}

Keywords: personnel, HR-strategy, stages of organizational life cycle, human capital

\section{INTRODUCTION}

The topic of building HR-strategy is relevant due to the fact that for dynamic development of the company it is necessary not only to attract the working and managerial staff in the region, but also to increase the quality of human capital. This objective needs to be realized both in the recruitment of new personnel and in the development of existing human resources.

Kolmar Group of companies includes 6 legal entities, which comprise 9 industrial facilities (3 mines, 3 concentrators, 2 open-pit mining sites, repair and production base). The main conceptual solutions presented in this article were used as the basis for the development of HR-strategies of company divisions.

Kolmar Coal Mining Company was founded in 2004 and is a large holding company uniting industrial enterprises for mining and processing of coking coals located in Southern Yakutia. The Kolmar Coal Mining Company is an anchor resident 
of the South Yakutia Advanced Special Economic Zone (ASEZ) and owns the Inaglinsky and Denisovsky mining and processing complexes in the Neryungrinsky District of Yakutia.

Balance reserves of the enterprise amount to more than 1 billion tons of coal. This provides the company with a resource base for at least 30 years of further operations.

Kolmar development projects take the lead in the strategic development of the Far East region.

As part of its continuous development strategy, the company adopted a multi-phase model to increase production capacity. Key development parameters are defined within each stage of the company. The main parameter is an increase in coal mining and coal concentrate production.

In order to achieve the company's key growth indicators, the company needs to increase its workforce by more than 4,500 people between 2021 and 2025 (i.e. by $100 \%$ ). The total number of personnel by the end of the period should be around 10,000 .

Table 1 shows the staffing headcount of Kolmar for 2019-2020.

Table 1. Average headcount for 2019-2020, persons

\begin{tabular}{|l|c|c|c|}
\multicolumn{1}{c|}{$\begin{array}{c}\text { Average } \\
\text { Headcount }\end{array}$} & 2019 & 2020 & $\begin{array}{c}\text { Abs. } \\
\text { Change } \\
\mathbf{2 0 2 0 - 2 0 1 9}\end{array}$ \\
\hline Total & 4221 & 4050 & 629 \\
\hline Production personnel & 3678 & 4373 & 695 \\
\hline Main production & 3130 & 3733 & 583 \\
\hline Auxiliary production & 528 & 640 & 112 \\
\hline Management & 543 & 477 & -66 \\
\hline
\end{tabular}

Source: Compiled by the authors

In accordance with Table 1 , there should be a reduction of 66 managerial staff. At the same time in 2020 it was not possible to attract about 1500 people according to the company's planned needs.

\section{MATERIALS AND METHODS}

The main research principle chosen in the paper is the cause-effect approach. Comparison and benchmarking of $\mathrm{HR}$ tools in the extractive industries has been used for selected developments.

Theoretical basis of the conducted research: works of domestic and foreign specialists.

Main information sources used in the preparation of the article:
- existing company development strategies;

- description of the company's business processes;

- organizational chart;

- internal company regulations (staff schedules, job descriptions, provisions, regulations, etc.);

- media publications;

- interviews with company employees.

The authors reviewed the main theoretical approaches that allow us to consider strategic planning in an organization as a unified holistic system $[1,2]$.

These models allow you to conceptually describe and fully take into account all the features of the current state of the company and its strategic goals and objectives:

- an increase in headcount by more than 4,500 employees (i.e. by $100 \%$ ) over two years;

- transition from the strategy of rapid market entry and capture of market share to the strategy of progressive development and increase in coal production;

- to become one of the leaders in coal mining and production of coke concentrate;

- implementation of a set of measures of social responsibility of business in the territory with difficult climatic living conditions [3, 4].

In order to select a theoretical framework for developing a suitable HR-strategy, an analysis of existing approaches to strategy typology was conducted [5]. Whichever type the overall HR strategy belongs to, its key components are always:

1) Human resource strategy;

2) Performance management strategy;

3) Personnel development strategy.

The choice of HR-strategy was based on the strategic direction of the company's development as a whole, and the stages of the organization's life cycle were also taken into account [6].

Since HR strategy always has an applied meaning and depends on the economic goals and objectives of the company, in order to choose the type of strategy it was first necessary to carry out an analysis of the current state of the group of companies. The next step was to determine what stage of the lifecycle the organization was at. Based 
on this, the matrices of strategic objectives were made, which made it possible to determine the type of HR-strategy, its priority areas and tools for implementation [7].

\section{RESULTS}

The strategy of Kolmar is to develop its production assets, increase coal production and processing, and gain leading positions in the industry. The task is vast, complex and long term. Therefore, not all previous shareholders were interested in it.

This strategy is related not only to the development of the company's production capacities and personnel, but also to the development of the region as a whole. Implementation of the project required large-scale relocation of workers and their families. The company's management understood that it was responsible for the fate of the people involved in this project. Therefore, the company understood that it had an obligation to ensure the development of critical infrastructure for employees and their families: medicine, education, cultural and recreational sphere, etc. And to do all this is necessary in a region with difficult climatic conditions and a small population.
Implementing all these tasks the company's management did not forget about the effectiveness of the company's activities, and the attracted human resources ensured the company's productivity and the growth of its economic indicators [8].

The formation of a motivated and competent team has become the most important component of the development strategy in this direction. This team should be multi-functional and include professionals from different fields: managers in the field of coal mining, financiers specializing in the coal industry, builders of coal mining facilities (mines, surface mines) and processing plants, etc. [9].

Therefore, almost immediately the company faced the task of forming the HR-strategy as a component of the overall development strategy of the company.

Two concepts are taken as the basis for selecting a leadership model:

- stages in the life cycle of companies.

- management styles (PAEI model).

Figure 1 shows the correlation between the stages of an organization's life cycle and their corresponding types of corporate culture.

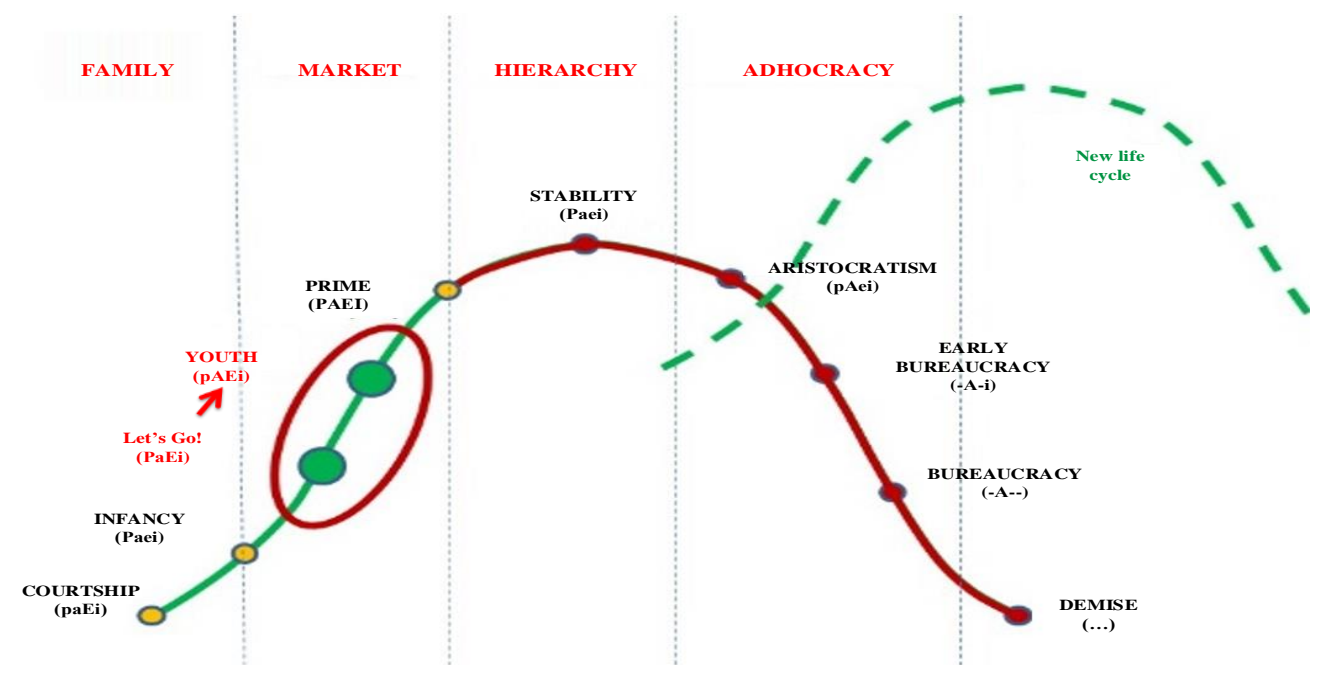

Figure 1. Correspondence of corporate culture types to the stages of an organization's life cycle Source: [2]

Figure 1 shows that a new life cycle (new direction of activity) should be arisen to prevent the organization's demise at the stage of transition from stability to aristocratism. During this period, a hierarchical type of corporate culture would be most preferable for the organization. At this stage of the company's development, a synthesis of two cultures - market and hierarchical - is best suited.
Skewing towards either of these cultures can lead to the company's demise. Therefore, all the processes of corporate culture change should be conducted in parallel and ensure that they are balanced.

Three functional strategies are distinguished within the general HR-strategy [10]:

1) Human resource strategy. 
2) Performance management strategy.

3) Human resources development strategy.

These functional strategies are implemented with any general HR strategy option. However, their specific content and toolkit depends on the type of overall strategy. In our case, it is a combination of a dynamic growth strategy and a profitability strategy with a transition from one to the other. The authors call it "Transition Strategy".

The goal of the human resource strategy is to create an environment to attract employees with competencies that match the company's strategy and corporate culture. This relates to workforce planning and structure, competency development needs analysis, recruitment policy, adaptation measures and staff retention.

Thus, the overall HR strategy of an organization focuses on creating opportunities for human capital to provide maximum contribution to the realization of strategic opportunities and ensure the competitiveness of the organization in the long run $[11,12]$.

Table 2 presents the main elements on which we focus our attention.

Table 2. Kolmar Group's corporate culture assessment parameters

\begin{tabular}{|l|l|l|}
\hline \multicolumn{1}{|c|}{ Parameter } & \multicolumn{1}{|c|}{ Market Component } \\
\hline $\begin{array}{l}\text { Company } \\
\text { milestones }\end{array}$ & $\begin{array}{l}\text { The organization is results-oriented. The main } \\
\text { thing is to fulfill the set tasks. }\end{array}$ & $\begin{array}{l}\text { A formalized and structured place. Procedures } \\
\text { control everything. }\end{array}$ \\
\hline Priorities & $\begin{array}{l}\text { Reputation, success, meeting targets, achieving } \\
\text { measurable goals. }\end{array}$ & $\begin{array}{l}\text { Ensuring stability, maintaining a smooth flow of } \\
\text { activities. }\end{array}$ \\
\hline Success & $\begin{array}{l}\text { Market penetration, market share increase, } \\
\text { market leadership. }\end{array}$ & $\begin{array}{l}\text { Cost reduction, reliability in all things, adherence } \\
\text { to plans. }\end{array}$ \\
\hline Leaders & Solid executives, competitors. & Coordinators and organizers who think rationally. \\
\hline $\begin{array}{l}\text { What connects the } \\
\text { company }\end{array}$ & The urge to win. & Formal rules and official policies. \\
\hline Management & Encouraging internal competition. & $\begin{array}{l}\text { Emphasis on job security, stability and } \\
\text { predictability. }\end{array}$ \\
\hline
\end{tabular}

Source: Compiled by the authors

As can be seen from Table 2, many tasks are contradictory. And at the same time, the company's task is to ensure the development of corporate culture simultaneously in two directions.

"Transition strategy" at Kolmar requires largescale systemic measures based on the adoption of new principles to improve the efficiency of HR management activities: speed, quality, reliability, flexibility and adaptability of all HR processes that have a direct impact on the company's performance indicators. The choice of strategy tools will be limited to populating the functional strategies for each of the two selected general HR strategies [13].

Functional Human Resources Strategy is aimed at attracting personnel meeting certain requirements. Rapid recruitment of a large number of employees reflects the trends of the Dynamic Growth Strategy, while the focus on high quality personnel in line with core competencies reflects the Profitability Strategy. At the same time, specific instruments may contain elements of each strategy at the same time. Kolmar is undertaking an ambitious and extremely challenging task: in a region with difficult climatic conditions and a lack of human resources, it is necessary to build a company that will become the center of the region's development in the long term.
Therefore, the task of large-scale resettlement of people to the region with unfavorable climatic conditions is implemented. In order to ensure effective work of these people it is necessary to use all resources, maximizing the potential of all methods of motivation and incentives [14].

For the selected employee categories (Middle and line management of production companies, Working specialties) financial incentives are of primary importance. At that, fairness and predictability of the remuneration system is very important for such employees [15].

However, non-monetary incentives are important for all categories of staff. The company's strategic goal is value-based management, and one of our values is building a healthy team of like-minded people who are loyal to the company.

Therefore, along with a detailed elaboration of the material incentive system, the company focuses on methods of non-material motivation.

Theoretical basis of Kolmar's motivation system:

1) Vladimir Gertschikov's Theory of Leading Motives;

2) John Stacey Adams' Theory of Justice; 
3) Susan Fowler's motivational status model;

4) Frederick Herzberg's two-factor model.

The structure of motivation for candidates for blue-collar jobs, middle and line management of companies is presented in Figure 2 [16].

The difference in approach is due to the fact that employees in managerial positions need to form a focus on the overall result of the team, not just on improving personal performance.

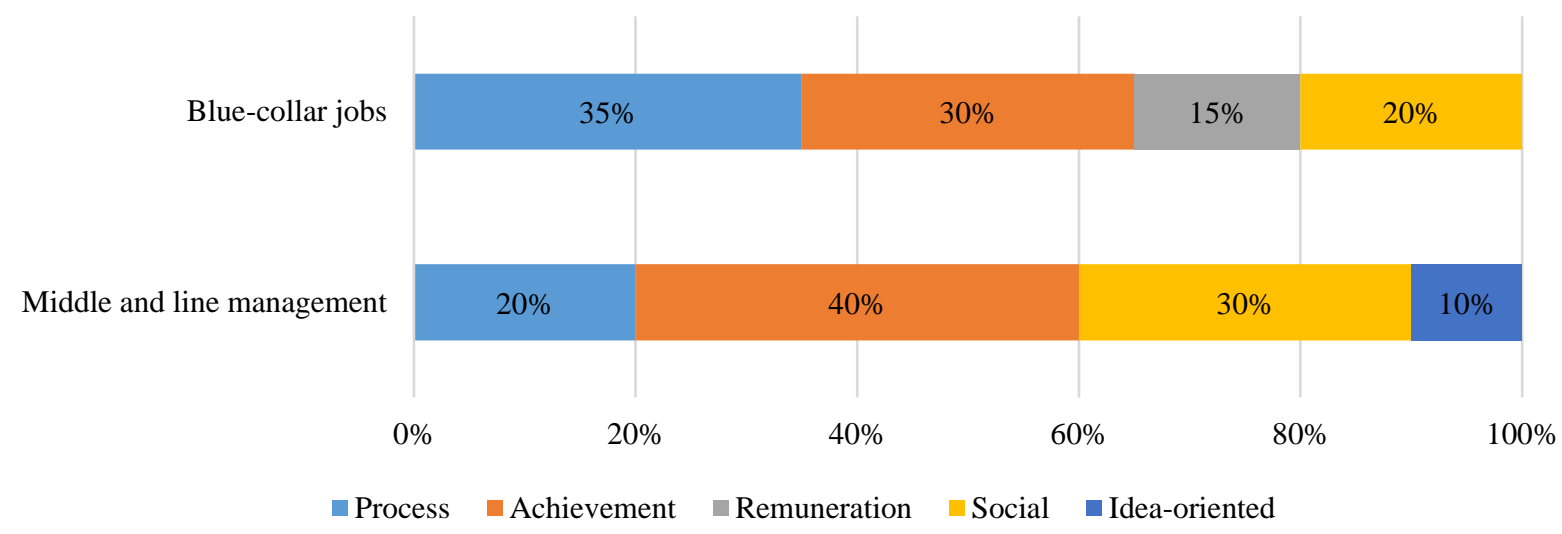

Figure 2. Incentive structure for candidates for blue-collar jobs, middle and line management in manufacturing companies

Source: Compiled by the authors

The company's remuneration is traditionally divided into a fixed part (salary) and a variable part (bonus). The frequency of bonus payment varies depending on the category of the position (the minimum period is 1 month, the maximum period is 1 year). A monthly bonus system has been established for the selected categories. Traditionally, this frequency allows for maximum impact.

In June 2020, as an experiment, the company decided to add an interim KPI on the work rate in two working mines. Compliance with this KPI is monitored every 2 weeks. If workers reach this KPI, the bonus is increased.

When we compared employees' activity in achieving KPIs using different evaluation approaches, it turned out that with the introduction of an additional control point affecting the size of the bonus, employees' activity increased many times over (Figure 3).

Company executives expected this innovation to increase output by $5-10 \%$. In fact, the output increased by $25 \%$ on average. At the same time, the premium portion increased by about $2-5 \%$. The company received such a powerful economic effect that it decided to extend this experience to all the working specialties of the enterprises included in Kolmar.

The second factor that was taken into account in the financial incentive scheme was the employee's personal involvement and manageability. By hiring a person, the company is not just hiring their "working hands". It hires them completely, with their own value system, personality traits, etc.

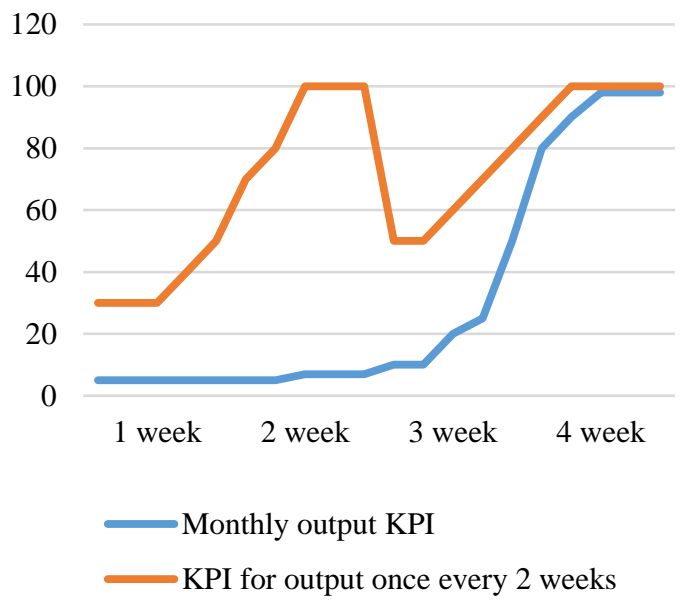

Figure 3. Activity of employees of working specialties at different periodicity of KPI control by output (in the context of 1 month) of Kolmar Group of companies

Source: Compiled by the authors

In order to be able to influence not only quantitative, but also qualitative performance, every manager should have tools to assess and influence employees. Employees must understand that their performance is not only evaluated through uniform indicators. The immediate supervisor also has the opportunity to influence his performance appraisal and therefore the amount of his bonus. 
Therefore, the variable part of the salary of these employees is additionally affected by the following indicators:

- for blue-collar jobs: (1) fulfillment of tasks and instructions of the manager, (2) manager assessment;

- for middle and line management of production companies: (1) achieving key management objectives, (2) 360-degree assessment, (3) fulfillment of tasks and

\section{Blue-collar jobs}

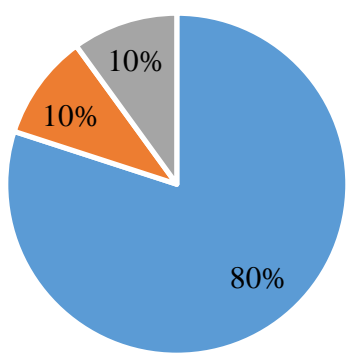

instructions of the manager, (4) manager assessment.

The share of these indicators is presented in Figure 4.

The size of the shares has not been finalized as the system is only being tested. But it is already evident that this approach helps to take into account a set of factors when considering in the motivation system that are significant for the effective labor behavior of an employee.

Middle and line management of production companies

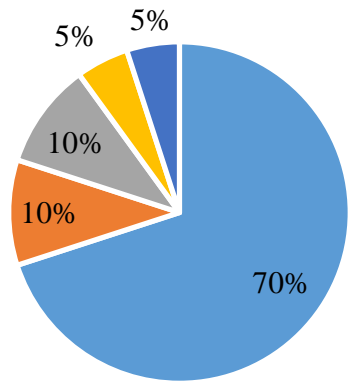

Figure 4. Indicators used for financial incentives for company employees.

Source: Compiled by the authors

It is necessary to observe the balance. The manager must have a tool of influence. At the same time, the system should objectively take into account the employee's contribution in order to avoid arbitrariness of the managerial staff in the field [17].

\section{DISCUSSION}

The authors expect a synergetic effect of the selected "Transition Strategy". The set of measures that the company implements as part of its implementation, currently actively contributes to the implementation of strategic objectives and ensure long-term competitiveness.

As the company is in the transition from the Let's Go phase to Youth, this has been accompanied by a rapid increase in headcount. First and foremost, the blue collar workers and the technical staff. By 2022 the number of these categories of personnel should double. This challenge is overlaid with regional issues. The region's potential has already been exhausted, as the vast majority of the region's workforce has already been hired by Kolmar Group and other companies in the region. In addition, all of the company's production resources are located in areas with a harsh climate (average January temperature - minus $30^{\circ} \mathrm{C}$, average annual temperature - minus $7^{\circ} \mathrm{C}$ ). The company's goal is to bring people to the region who are capable of realizing the company's ambitious strategic goals in permafrost conditions. Therefore, the company faces a number of challenges related to large-scale personnel recruitment, which is reflected in the personnel policy of the Kolmar Coal Mining Company.

The candidate flow enhancement measures used at Kolmar are shown in Figure 5.

Such a large-scale operation imposes additional requirements in terms of staff search and recruitment.

The peculiarity of forming the company's talent pool at the moment is that in the implementation of the large-scale task of selecting employees from different regions it is required to hire everyone who is potentially suitable for this job. And further, there is a need to upgrade the skills of newly hired staff as quickly as possible. The talent pool is supposed to be formed for the development of basic and middle management positions in the first place. With the rapid increase in the number of employees, it is in this niche that staff shortages are predicted. 


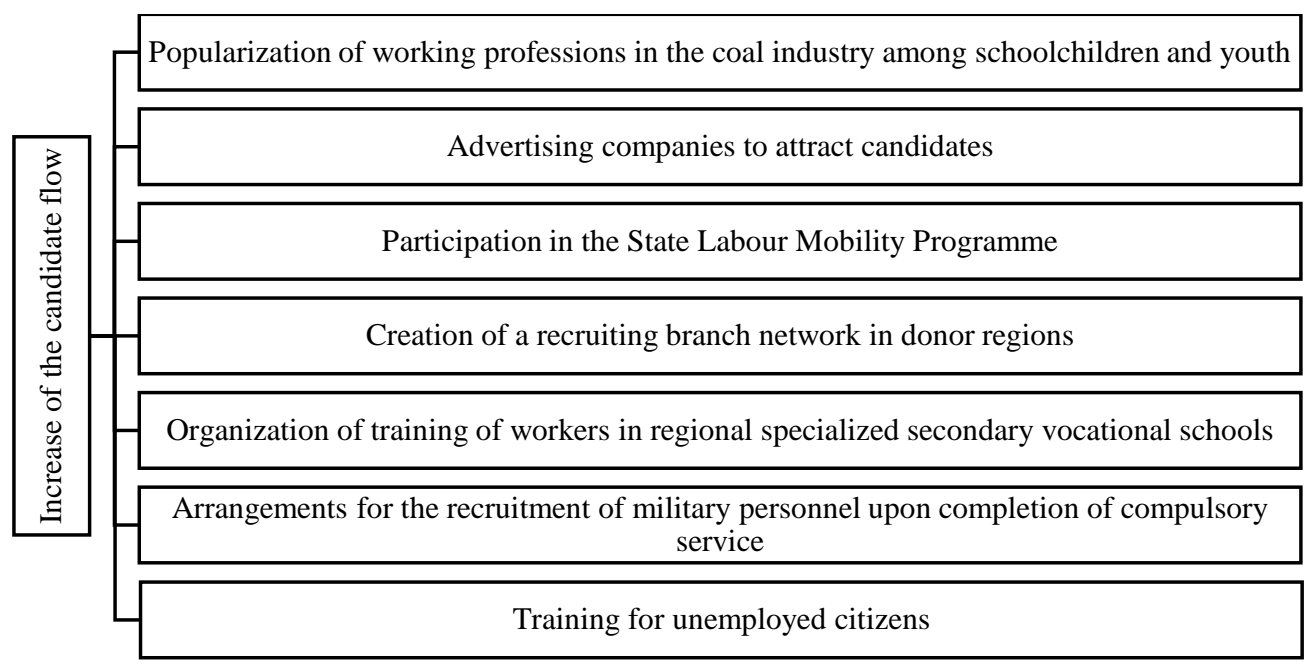

Figure 5. Measures to increase candidate flow used at Kolmar Group

Source: Compiled by the authors

It is proposed to take as a basis the matrix of employee task readiness levels by Paul Hersey and Ken Blanchard [18]. Therefore, it is planned to develop the talent pool in 2021-2022.

It is proposed to take as a basis the matrix of employee task readiness levels by Paul Hersey and Ken Blanchard [18].

Financial incentives for miners should not depend too much on the amount of coal produced by any means. It is important to comply with environmental regulations and work safety in the mine, to use modern production technologies and to control the safety of the work performed.

\section{CONCLUSION}

The main results of the conducted research consist in solving the complex task of providing a dynamically developing company with high-quality personnel in the conditions of constant growth of the number of employees and constantly increasing requirements to the level of development, qualification, competences of human resources. The most important applied task of HR-strategy realization is to increase productivity of each employee, development of his/her personal and professional qualities.

The novelty of the approach lies in the fact that all activities are planned to be deployed in parallel. This will require ensuring maximum involvement of senior and middle management as well as line managers.

Tasks on such a scale have never been solved in the Far East region. South Yakutia is a promising region for the development of the Far East. However, difficult climatic and socio-economic conditions previously hindered industrial development at the rate currently planned. The region itself, with its harsh climate and underdeveloped social infrastructure, was not attractive to workers until recently. The company has to develop unique measures to attract, retain, motivate and develop staff at scale.

That is why the experience gained by Kolmar in the development process can serve as a basis for the development of the extractive industries in the region as a whole. The results obtained could also be applied to areas with similar parameters.

It can be said that the problems to be solved are unique and have no theoretical or practical description.

\section{AUTHORS' CONTRIBUTIONS}

The authors made an equal contribution to the study: collection and analysis of material; definition of goals and objectives, research methods; formulation and scientific substantiation of conclusions, registration of key research results in the form of an article.

\section{REFERENCES}

[1] C.D. Mc Cauley, Ch.J. Palus. "Developing the theory and practice of leadership development: A relational view", The Leadership Quarterly, 2021, vol. 32(5), p. 101456. 
[2] M. Nadeem, R. Zaman, T. Suleman, N. Atawnah, "CEO ability, career concerns, firms' lifecycle and investments in intellectual capital", International Review of Economics \& Finance, 2021, vol. 75, pp. 237-251.

[3] T. Naegler, C. Sutardhio, A. Weidlich, T. Pregger, "Exploring long-term strategies for the german energy transition - A review of multi-Sector energy scenarios", Renewable and Sustainable Energy Transition, 2021, vol. 1, p. 100010.

[4] C.E. Oehlhorna, Ch. Maier, S. Laumer, T. Weitzel, "Human resource management and its impact on strategic business-IT alignment: A literature review and avenues for future research", The Journal of Strategic Information Systems, 2020, vol. 29(4), p. 101641.

[5] Z. Adiguzel, M.F. Ozcinar, H. Karadal, "Does servant leadership moderate the link between strategic human resource management on rule breaking and job satisfaction?", European Research on Management and Business Economics, 2020, vol. 26(2), pp. 103-110.

[6] D.M. Ivantsevich, "Human resources management: basics of personnel management" [Chelovecheskie resursy upravleniya: osnovy upravleniya personalom], Moscow: Delo, 2006, 300 p. (in Russ.).

[7] A. El-Kassar, G.K. Dagher, S. Lythreatisc, M. Azakir, "Antecedents and consequences of knowledge hiding: The roles of HR practices, organizational support for creativity, creativity, innovative work behavior, and task performance", Journal of Business Research, 2022, vol. 140, pp. 1-10.

[8] T.N. Lobanova, "Motivation and stimulation of labor activity. Textbook and Practice for Bachelors" [Motivaciya i stimulirovanie trudovoj deyatel'nosti. Uchebnik i praktikum dlya akademicheskogo bakalavriata], Moscow: Yurajt, 2015, 282 p. (In Russ).

[9] T.Yu. Bazarov, "Human Resources Management" [Upravlenie personalom]: Textbook, Moscow: ACADEMIA, 2013. (In Russ).

[10]F. Susan, "Why aren't they working? A new look at employee motivation" ["Pochemu oni ne rabotayut? Novyj vzglyad na motivaciyu sotrudnikov"], Moscow: Alpina Publisher, 2020. (In Russ.).

[11]S. Kaczmarek, "Mastering fourth industrial revolution through innovative personnel management - A study analysis on how gamebased approaches affect competence development", IFAC-Papers OnLine, 2019, vol. 52(13), pp. 2332-2337.

[12] T.K. Harutyunyan, "What do you do with the strategy. Guidance on the strategic development of the company" ["Chto vam delat' so strategiej. Rukovodstvo po strategicheskomu razvitiyu kompanii”], Mann: Ivanov \& Ferber, 2013, 237 p. (in Russ.).

[13] S.S. Golubev, S.S. Chebotarev, V.D. Sekerin, A.E. Gorokhova, "Development of employee incentive programmes with regard to risks taken and individual performance", International Journal of Economic Research, 2017, vol. 14(2), pp. 37-46.

[14] S.S. Golubev, V.I. Volkov, A.G. Shcherbakov, V.D. Sekerin, A.E. Gorokhova, "Manpower Support for Digital Technology Implementation Processes in Industrial Enterprises", International Journal of Engineering and Advanced Technology, 2019, vol. 8(3), pp. 414420.

[15]E. Dyundik, S. Golubev, A. Makhova, L. Gurtskoy, "Development of human capital in the military industrial complex of Russia in the context of digital transformation", E3S Web of Conferences, 2020, vol. 217(153). DOI: 10.1051/e3sconf/202021706005

[16] V.I. Gertschikov, "Human Resources Management. An employee is a company's most effective resource. Tutorial" [Upravlenie personalom. Rabotnik - samyj effektivnyj resurs kompanii. Uchebnoe posobie], Moscow: Infra-M, 2011. (In Russ.).

[17] W. Dauth, P. Haller, "Is there loss aversion in the trade-off between wages and commuting distances?", Regional Science and Urban Economics, 2020, vol. 83, p. 103527.

[18]Ch. Kiersch, N. Gullekson, "Developing character-based leadership through guided selfreflection", The International Journal of Management Education, 2021, vol. 19(3), p. 100573. 